\title{
The island-scale internal wave climate of Moorea, French Polynesia
}

\author{
James J. Leichter, ${ }^{1}$ M. Dale Stokes, ${ }^{1}$ James L. Hench, ${ }^{2}$ Jan Witting, ${ }^{3}$ and Libe Washburn ${ }^{4}$
}

Received 31 January 2012; revised 23 April 2012; accepted 1 May 2012; published 8 June 2012.

[1] Analysis of five-year records of temperatures and currents collected at Moorea reveal strong internal wave activity at predominantly semi-diurnal frequencies impacting reef slopes at depths $\geq 30 \mathrm{~m}$ around the entire island. Temperature changes of $1.5^{\circ} \mathrm{C}$ to $3^{\circ} \mathrm{C}$ are accompanied by surges of upward and onshore flow and vertical shear in onshore currents. Superimposed on annual temperature changes of approximately $3^{\circ} \mathrm{C}$, internal wave activity is high from Oct-May and markedly lower from Jun-Sep. The offshore pycnocline is broadly distributed with continuous stratification to at least $500 \mathrm{~m}$ depth, and a subsurface fluorescence maximum above the strong nutricline at approximately $200 \mathrm{~m}$. Minimum buoyancy periods range from 4.8 to $6 \mathrm{~min}$, with the maximum density gradient occurring at 50 to $60 \mathrm{~m}$ depth in summer and deepening to approximately 150 to $200 \mathrm{~m}$ in winter. The bottom slope angle around all of Moorea is super-critical relative to the vertical stratification angle suggesting that energy propagating into shallow water is only a portion of total incident internal wave energy. Vertical gradient Richardson numbers indicate dominance by density stability relative to current shear with relatively limited diapycnal mixing. Coherence and lagged cross-correlation of semi-diurnal temperature variation indicate complex patterns of inter-site arrival of internal waves and no clear coherence or lagged correlation relationships among island sides. Semi-diurnal and high frequency internal wave packets likely arrive on Moorea from a combination of local and distant sources and may have important impacts for nutrient and particle fluxes in deep reef environments.

Citation: Leichter, J. J., M. D. Stokes, J. L. Hench, J. Witting, and L. Washburn (2012), The island-scale internal wave climate of Moorea, French Polynesia, J. Geophys. Res., 117, C06008, doi:10.1029/2012JC007949.

\section{Introduction}

[2] Internal waves are ubiquitous features of coastal environments and islands where irregular bathymetry, stable water column density stratification, and tidally forced currents cooccur [e.g., Garrett and Munk, 1979; Apel, 1988; Farmer and Armi, 1999; Helfrich and Melville, 2006]. Frequently generated at or near the shelf break, vertical oscillations of isopycnal surfaces can be detected close to sites of generation and can also take on the form of groups of waves traveling long distances $(>10 \mathrm{~s}$ to $100 \mathrm{~s} \mathrm{~km})$. Surface manifestations of internal wave trains are widespread in both temperate and tropical waters, seen as groups of long, parallel banded surface slicks in

\footnotetext{
${ }^{1}$ Scripps Institution of Oceanography, University of California, San Diego, La Jolla, California, USA.

${ }^{2}$ Nicholas School Marine Laboratory, Duke University, Beaufort, North Carolina, USA.

${ }^{3}$ Sea Education Association, Woods Hole, Massachusetts, USA.

${ }^{4}$ Geography Department, University of California, Santa Barbara, California, USA.

Corresponding author: J. J. Leichter, Scripps Institution of Oceanography, University of California, San Diego, La Jolla, CA 92093, USA. (jleichter@ucsd.edu)

C2012. American Geophysical Union. All Rights Reserved.
}

remotely sensed images particularly via synthetic aperture radar [Apel and Farmer, 2002]. Internal waves running into shallow water tend to become highly nonlinear and their breaking can generate strong, turbulent near-bottom flows, and can constitute an important component of total tidal energy dissipation to turbulence and mixing [St. Laurent and Garrett, 2002; St. Laurent and Nash, 2004; Helfrich and Melville, 2006]. The breaking dynamics and net transport of mass and momentum are dependent on the extent of stratification and seafloor slope angle [Phillips, 1977], and erosion of seafloor sediments by near-bottom currents generated in breaking internal waves is thought to be one factor shaping continental slopes [Cacchione et al., 2002].

[3] Recognized biological consequences of internal waves in shallow water ecosystems include rapid, large variations in temperature likely to influence physiological and metabolic processes in marine organisms [e.g., Leichter et al., 2006; Roder et al., 2010], transport of buoyant surface materials and marine invertebrate larvae close to shore [Pineda, 1991, 1994; Shanks et al., 2000], injection of sub-thermocline nutrients into the euphotic zone with potential to enhance local primary production [e.g., Wolanski and Pickard, 1983; Sandstrom and Elliott, 1984; Leichter et al., 2003; Lucas et al., 2011], and enhanced near-bottom fluxes of particles and suspended material [Leichter et al., 1998]. In coral reef 
environments recurring exposure to cool water due to internal waves may limit the lower depth distribution of corals and other warm-adapted, stenothermal species with limited thermal tolerance [Wolanski et al., 2004], but may also buffer deep reefs from thermal stress associated with high surface temperatures [Bak et al., 2005]. Spatial variation in internal wave impacts among different sides of islands can influence species community composition, and can influence the growth, biomass, protein content, and physiological performance of corals [Roder et al., 2010]. However, relatively little is known about the seasonality and coherence of internal wave impacts at the scales of whole coral reefs and islands (e.g., scales $\sim 5$ to $10 \mathrm{~s}$ of $\mathrm{km}$ ).

[4] The objective of this study is to examine seasonal patterns of internal wave impacts at the scale of a whole island in the central South Pacific. Moorea, at the eastern end of the Society Island archipelago, is typical of high volcanic islands that are widely distributed in the tropical Pacific, and often surrounded by coral reefs. It is the site of the Moorea Coral Reef Long-term Ecological Research Project initiated in 2004 with a focus on the ecological consequences of physicalbiological interactions. TOPEX/Poseidon altimetry observations [Ray and Mitchum, 1997; Egbert and Ray, 2001], and models of the conversion of barotropic to baroclinic energy [Niwa and Hibiya, 2001; Garrett and Kunze, 2007] suggest that the Society Island archipelago and the Tuamotu Islands to the northeast are zones of extensive internal wave generation. Local observations of internal waves impacting the north shore of Tahiti have been reported in one study with relatively short (2-3 months) deployments of thermistor chains and vectoraveraging current meters at 15 to $>800 \mathrm{~m}$ depths [Wolanski and Delesalle, 1995a]. In addition to presenting evidence of internal waves at diurnal and semi-diurnal frequencies Wolanski and Delesalle [1995a] speculated that cool, nutrient-rich water transported onto the reef slope might be further advected into shallow water by secondary flows associated with surface waves interacting with the reef spur and groove topography. The limited study duration in Wolanski and Delesalle [1995a] and availability of data from only one side of Tahiti precluded analysis of longer term, seasonal patterns or consideration of internal wave impacts at the island scale. Unresolved questions for Moorea include: (1) What is the incidence and depth distribution of internal waves? (2) How does internal wave activity vary across the scale of the whole island? (3) What are the seasonal patterns of internal wave activity? (4) What are the generating mechanisms of internal waves arriving on Moorea and are they local or distant? (5) What are the biological effects and ecological consequences of internal wave activity? Here we address the first three of these questions by examining the variation and spatial coherence of internal wave activity around Moorea at the whole-island scale. We analyze reef temperature and water column current observations collected at multiple sites around the island over a five-year period from 2005 2010 , and describe seasonal variation in water column hydrographic structure from data collect during the study in 2009 and historically between 1979 and 2005 .

\section{Methods}

\subsection{Study Sites}

[5] Moorea $\left(17^{\circ} 30^{\prime} \mathrm{S}, 149^{\circ} 50^{\prime} \mathrm{W}\right)$ is a high-relief volcanic island, with mountain peaks to $900 \mathrm{~m}$, located toward the eastern end of the Society Island archipelago in the central tropical South Pacific (Figure 1). The island is approximately $60 \mathrm{~km}$ in circumference (area ca. $135 \mathrm{~km}^{2}$ ) and situated close (ca. $15 \mathrm{~km}$ ) to the larger island of Tahiti. Moorea and Tahiti are thought to have last been volcanically active approximately 2 myr ago with Tahiti being the younger island [Dymond, 1975]. Island age across the Society Island archipelago increases from southeast to northwest corresponding to a graduation from younger, high volcanic islands to older partially submerged atolls along a complex topography that rises to the ocean surface from the abyssal seafloor at depths of approximately 3500 to $4000 \mathrm{~m}$. Moorea is almost entirely surrounded by a fringing/barrier coral reef separating a protected inshore lagoon from the open ocean, with a series of reef breaks and passes that allow water exchange between the lagoon and the open ocean. On the north shore of Moorea the lagoon connects to two large bays that are approximately $5 \mathrm{~km}$ in length and $1 \mathrm{~km}$ in width with depths of 20 to $30 \mathrm{~m}$ along their length.

[6] Large-scale flow past the islands is dominated by the westward flow of the South Equatorial Current forming the northern region of the large anticyclonic subtropical gyre in the tropical South Pacific [Rougerie and Rancher, 1994]. Surface currents near the island and in the lagoon are also influenced by the prevailing Southeast Trades and diurnal sea breeze. Flow across the reef crest and in the lagoon is additionally influenced by wave setup on the fore reef. During periods of high incident wave energy the forcing of water across the reef crest creates a nearly unidirectional flow into the lagoon and consistent circulation pattern out of the reef passes on the north shore [Hench et al., 2008]. Similar circulation patterns occur during periods of high wave exposure on the southwest shore (authors personal observations). The seasonal climate is characterized by a warm, wet season from Nov-Apr and a cooler and drier season typically from May-Oct. Associated with the proximity of the Intertropical Convergence Zone, rainfall can be heavy, especially from Dec-Mar. Surface conditions can also be influenced by local storms including strong, episodic northward winds locally termed "Maramu" that force surface waters out of the bays and lagoons with compensatory inflow of subsurface water into the deep channels of the reef passes [Wolanski and Delesalle, 1995b]. The outer reef slopes around Moorea are characterized by low (1 to $2 \mathrm{~m}$ ) coral spur and groove formations running approximately normal to reef slope isobaths. Historically Moorea's reefs have been characterized by high abundance of predominantly branching corals in the Pocilloporidae and Acroporidae families, as well as massive corals in the family Poritidae. Due to repeated biological and physical disturbance during the past several decades, most of the branching coral colonies are relatively small (ca. 10 to $50 \mathrm{~cm}$ ) and a significant outbreak of the coralivorous sea star Acanthaster plancii resulted in large-scale coral mortality and markedly reduced coral cover on the whole island scale between 2006 and 2008 [Adam et al., 2011].

[7] Five study sites (Figure 1, Sites A-E) were established on the fore reef slope around Moorea and accessed by standard SCUBA diving. Bottom temperature at 10 to $40 \mathrm{~m}$ depth was measured at each site, water column currents were measured at Sites A, C, and D, and water column temperature was measured with a vertical mooring array located on 


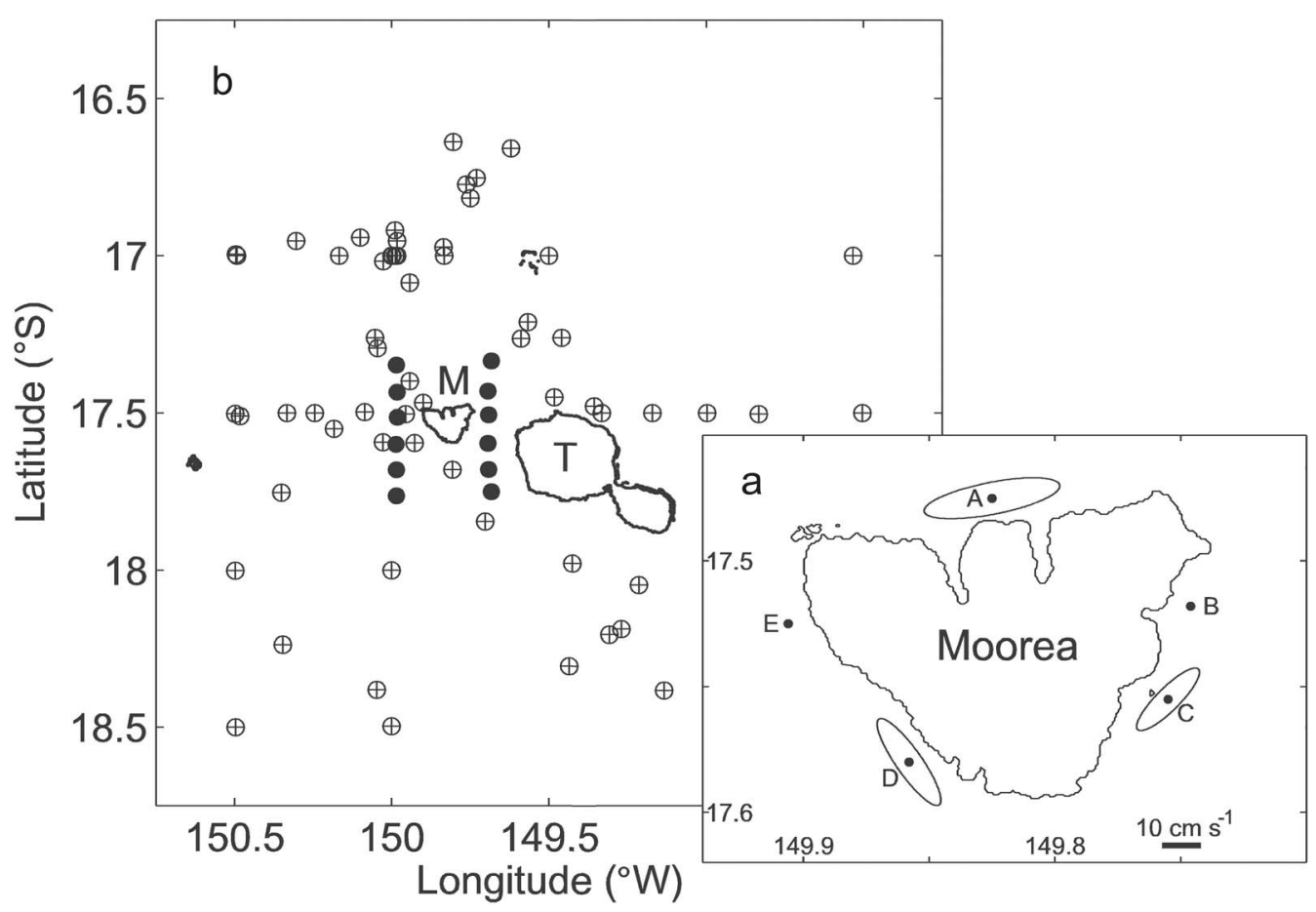

Figure 1. Study sites around the island of Moorea. (a) Inset shows locations of 5 main sampling sites, A-E indicated by solid circles. Current variance ellipses are shown for water column integrated velocities at Site A, C, and D. Major and minor axes of the ellipses correspond to the variance in the alongshore and cross-shore velocities, with magnitude indicated by the scale bar $\left(10 \mathrm{~cm} \mathrm{~s}^{-1}\right)$. (b) Locations of 12 CTD stations sampled on 25-26 Jan 2009 (solid circles) 64 stations sampled between 1979 and 2005 with data available through the World Ocean Data Base (crossed open circles) are shown.

the $50 \mathrm{~m}$ isobath at Site A. Details of each type of sampling are described below. Offshore water column hydrographic data were collected at a grid of stations surrounding Moorea in Jan 2009. Hydrographic data sampled during earlier studies and available as part of the National Oceanographic Data Center's World Ocean Database (http://www.nodc.noaa.gov/ OC5/WOD/pr_wod.html) were analyzed to investigate seasonal patterns of water column stratification (see below).

\subsection{Temperature and Current Velocity Time Series}

[8] All temperature time series were collected continuously at $120 \mathrm{~s}$ intervals with Seabird Electronics SBE 39 recording sensors $\left(0.001{ }^{\circ} \mathrm{C}\right.$ temperature resolution, ca. $2 \mathrm{~s}$ response time) attached to flat plates affixed to the reef surface on the $10,20,30$, and $40 \mathrm{~m}$ isobaths at each study site. The instruments at each site were situated along a transect running down the reef slope and parallel to reef spur and groove formations. Measurements were initiated in late 2004 at Site A with deployments added in 2005 at Sites B and C, and 2006 at Sites D and E. In mid-2007 a vertical mooring consisting of 7 temperature recorders spaced at $7 \mathrm{~m}$ vertical intervals was deployed on the $50 \mathrm{~m}$ isobath at Site A, directly downslope from the $40 \mathrm{~m}$ sampling location. The bottom temperature recorder on the vertical mooring was positioned $1 \mathrm{~m}$ above the base of the mooring and the data from that location are used as a measure of bottom temperature at $50 \mathrm{~m}$ depth. The top of the mooring was positioned below the surface at approximately 8 to $11 \mathrm{~m}$ depth to reduce the risk of loss due to boat traffic and fishing. The top recorder sampled pressure along with temperature, and the pressure data were used to measure any knockdown of the mooring by currents. The top of the mooring was typically within 1-3 m depth of its still-water position, but occasional knockdown as large as 7-8 $\mathrm{m}$ was recorded during periods of strong alongshore current. The depth deviation of the top of the mooring was used to estimate the true vertical position for each sensor by approximating the mooring cable as a series of straight line segments with an angle of deflection and position determined trigonometrically. We assume for this purpose that treating the mooring knockdown as a straight line rather than a catenary curve is reasonable approximation. The total depth deviations of loggers along the mooring line ranged from approximately $5-15 \%$ of their nominal or still-water positions. The minimum buoyancy period supported by the density stratification in Moorea was 4.8 to $6.3 \mathrm{~min}$ (see hydrographic sampling below) thus the $120 \mathrm{~s}$ sampling should adequately capture high frequency variation in the system. Individual instrument deployments typically lasted 5 to 7 months. Instruments retrieved at the end of deployments were typically swapped in the field with newly programmed loggers to maintain continuous data records. Where short gaps (ca. $1 \mathrm{~d}$ ) existed due to deployment logistics or in one case where a large gap occurred due to a flooded recorder and two cases when recorders were lost due to a cyclone, the missing observations in time series were filled with blank values. Clock drift measured upon recorder retrieval was small, 
typically in the range of 2 to $5 \mathrm{~s}$ per month and was therefore disregarded.

[9] Water column current velocity at Sites A, C, and D was measured with bottom-mounted, upward-looking acoustic Doppler current meters (RD Instruments $600 \mathrm{kHz}$ Workhorse Sentinel with internal pressure sensors) deployed on the $40 \mathrm{~m}$ depth isobaths and sampling 1 min ensembles of 20 pings per ensemble in $2 \mathrm{~m}$ vertical bins through the entire water column. This sampling mode provided horizontal and vertical velocities with estimated error standard deviation of $0.7 \mathrm{~cm} \mathrm{~s}^{-1}$. Current meters were deployed continuously recording for 5 to 7 months before being retrieved and redeployed typically within $1 \mathrm{~d}$. Nearly continuous current measurements were made from early 2005 through 2010 at Site A, from late 2006 through 2010 at Site D, and from 2007 to 2008 at Site C.

\subsection{Hydrographic Sampling}

[10] Water column hydrographic data were collected during a $48 \mathrm{~h}$ cruise on the research vessel SSV Robert C. Seamans on 25-26 January 2009. A grid of 12 stations was sampled along two parallel transects on the west and east sides of Moorea (Figure 1). At each station a single hydrocast was made to $550 \mathrm{~m}$ depth with a Seabird Electronics SBE-19plus conductivity-temperature-depth (CTD) profiler with chlorophyll $a$ fluorometer, dissolved oxygen sensor, photosynthetically active radiation (PAR) sensor, and a rosette of twelve, 12-L Niskin bottles. At four of the stations water samples were collected at depths of 40,60, 90, 110, 140, 200, 250, 300, 400 , and $500 \mathrm{~m}$. Water samples were filtered onboard the ship through $0.7 \mu \mathrm{m} \mathrm{GF} / \mathrm{F}$ filters and frozen for subsequent nutrient analysis. Concentrations of nitrate, soluble reactive phosphate, silicate, and ammonium were subsequently determined on a Lachat Instruments QuikChem 8000 flow injection analyzer at the Marine Sciences Institute, University of California at Santa Barbara. Duplicate samples from each Niskin bottle were analyzed and resulting values were averaged to obtain a single concentration estimate for each nutrient analyte from each sample bottle.

\subsection{Data Analyses}

[11] Temperature records from 10 to $50 \mathrm{~m}$ depth at Site A for the period July 2007 to Mar 2010 were divided into two seasons corresponding to Oct-May and Jun-Sep in each year. Power spectra were then calculated for each depth in each of the two seasons. A 1/40 cycle-per-hr (cph) high-pass filter was used to retain only the variability at frequencies faster than the local inertial frequency of $1 / 39.8 \mathrm{cph}$. To investigate the frequencies of variation in the temperature time series power spectra with $95 \%$ confidence intervals were then calculated using the Welch average periodogram method [Emery and Thomson, 1997; Trauth, 2010]. Window length was set to $2^{15}(32,768$ points, corresponding to 45.51 day of the 2-min interval data) with application of a Hamming window and $50 \%$ overlap. The average power spectrum for each depth was then normalized by multiplying power by $1 /$ frequency to yield power spectral density. An overall spectrogram of spectral power as a function of frequency and time was also calculated with the 5-yr time series from the $40 \mathrm{~m}$ depth sampling station at Site A. To investigate potential influence of fortnightly and longer period tidal processes on temperature patterns at Moorea power spectra were also calculated for frequencies corresponding to periods up to $96 \mathrm{~d}$.

[12] Evidence of internal waves and internal wave seasonality were also investigated within the time series of water column currents collected at $40 \mathrm{~m}$ depth at Site A. We calculated the cross-shore component of horizontal shear squared, $S_{\text {cross }}^{2}=(\partial v / \partial z)^{2}$ where $v$ is the cross-shore component of velocity and $z$ is depth calculated as the finite difference between successive vertical bins throughout the water column for the current records from Site A for the period 2005-2010. The resulting time series of $S_{\text {cross }}^{2}$ was then divided into seasons corresponding to Oct-May and Jun-Sep in each year and mean values of $S_{\text {cross }}^{2}$ within each season were calculated for the entire water column. Season-specific power spectra of $S_{\text {cross }}^{2}$ for the water column bin closest to the bottom $(3.5 \mathrm{~m}$ above the bottom) were calculated as described above for the temperature time series. Cross-spectra between bottom temperature and current shear were also calculated using the same spectral parameters described above.

[13] To assess the potential for diapycnal mixing on the forereef associated with current shear and internal waves we computed time series of the gradient Richardson number: $R i=N^{2} / S^{2}$, where $N^{2}=-(g / \rho) \partial \rho / \partial z$ is the buoyancy frequency squared, describing the strength of vertical stratification with $g$ being the acceleration due to gravity, $\rho$ being density, $z$ being depth, and $S^{2}=(\partial u / \partial z)^{2}+(\partial v / \partial z)^{2}$ is the total horizontal shear where $u$ and $v$ are the orthogonal components of horizontal velocity. This form of the Richardson number describes the relative balance between the stabilizing influence of the vertical density stratification and the potential for mixing caused by current shear. A critical value, $R i_{c r}=0.25$, implies a balance between stability from vertical stratification, and instabilities produced by vertical shear. $R i$ values smaller than $R i_{c r}$ indicate potential for diapycnal mixing. Vertical shear and density gradient were computed for the current meter and thermistor string data from at Site A. Because the vertical current profiles were sampled at $2 \mathrm{~m}$ vertical bin resolution while the temperature profiles were sampled at $7 \mathrm{~m}$ vertical intervals, the temperature and velocity profiles were spline interpolated (using the csaps function in Matlab) to common vertical levels using $6 \mathrm{~m}$ intervals as a compromise resolution. Interpolated values were then finite differenced to produce profiles of the vertical gradients. Temperature profile data were converted to density profiles using a standard equation of state and assuming a constant salinity of 36.0 representative of Moorea in our hydrographic sampling and reported by Hench et al. [2008]. Assuming constant salinity likely produces an underestimate of the total density variability. However, because the vertical variation in salinity is much less than the vertical variation in temperature, the impact of assuming constant salinity should be small. A time series of the gradient Richardson number normalized by $R i_{c r}$ was computed for a period of continuous current meter and thermistor string data at Site A from Dec 2007 to Mar 2008, and the proportion of time periods when normalized $\mathrm{Ri}$ / $R i_{c r}<1$ was calculated through the water column. For the normalized time series $R i / R i_{c r}$ values $<1$ indicate periods of potential diapycnal mixing due to current shear.

[14] Island scale patterns of temperature variation across sites were analyzed by calculating both the coherence and 

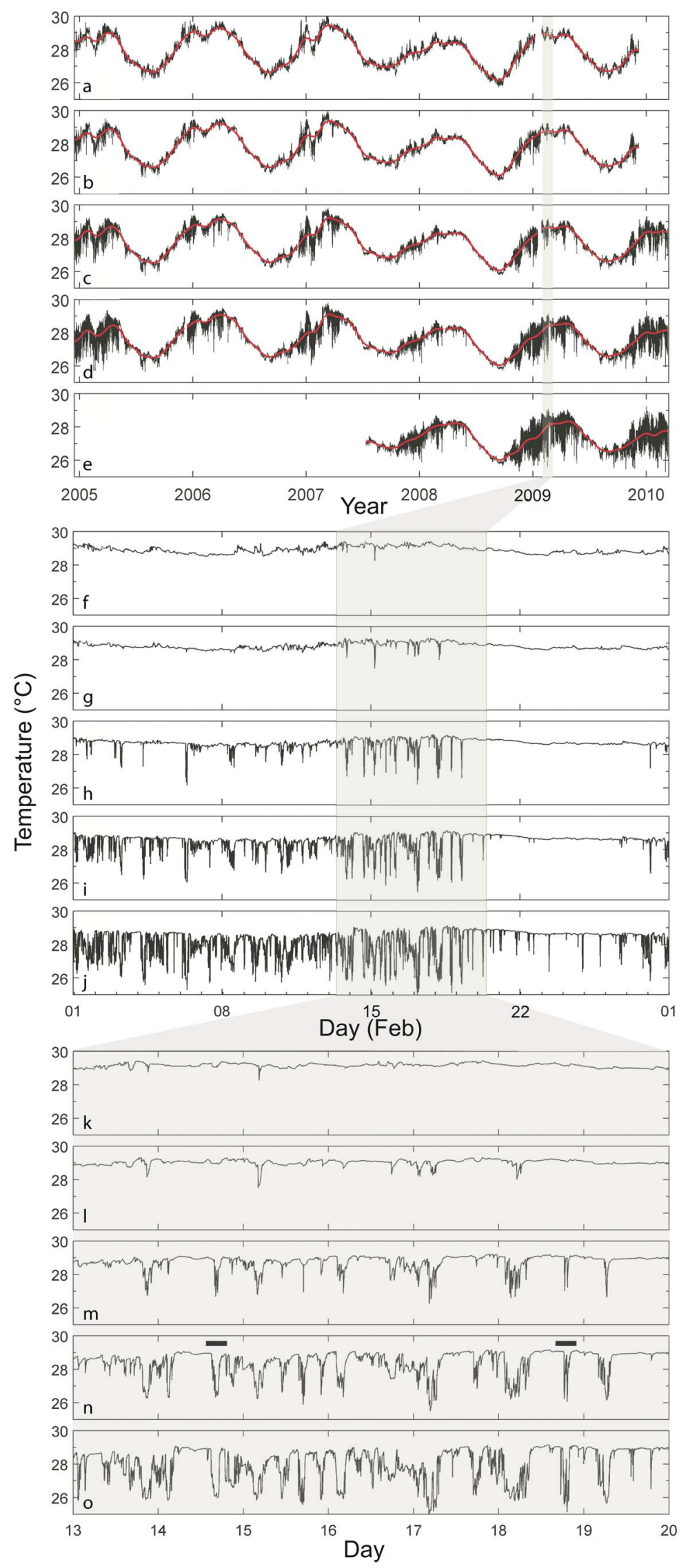

Figure 2 
the lagged cross correlation of signals from $40 \mathrm{~m}$ depth across all pairings of the 5 sites. These analyses were focused on patterns at the semi-diurnal frequency where the power spectra showed the major concentration of variability. Continuous temperature data from $40 \mathrm{~m}$ depth at each of the 5 sites A-E were available for a 31-wk period from mid Dec 2009 to near the end of Jul 2010. Coherence (the frequencyspecific correlation) was estimated for each of the 10 site pairings following Emery and Thomson [1997] and Trauth [2010]. The 31-wk record was divided into 7-d data segments (5040 points) and in each data segment the cross spectra, mean squared coherence, and phase shift were estimated. A significance threshold for a coherence of zero was calculated for alpha $=0.05$ (95\% confidence interval) following Emery and Thomson [1997] who show that the equivalent degrees of freedom for a Hamming window is $2.5164 *(L / M)$ where $L$ is the number of data points in the data segment and $\mathrm{M}$ is the width of the Hamming window. Phase shifts were estimated for points when the coherence exceeded the significance threshold. Coherence for the tidal signal of water level measured by pressure sensors on the current meters at Sites A and D was also estimated. The lagged cross correlation of temperature variation among site pairings was calculated on the signals from each site after applying a band-pass filter to remove major variation outside of the semi-diurnal band (chosen as periods between 9 and $14 \mathrm{~h}$ ). Lagged cross correlation was then calculated for each of the 31,7-d intervals. Lags were calculated corresponding to \pm 120 points $(240 \mathrm{~min})$, i.e., a shift of one signal by $\pm 4 \mathrm{~h}$ relative to the other. The maximum correlation coefficient and corresponding lag for each 7-d interval was recorded, and the averages, maxima, and minima of the correlation coefficient and lag were examined for each site pairing.

[15] Estimates of the seasonal variation in local water column stratification were made by analyzing historical data within the World Ocean Database for a $2^{\circ}$ by $2^{\circ}$ sampling area surrounding Moorea and Tahiti. 64 historical hydrocasts with maximum depth $>200 \mathrm{~m}$ were found in the database sampled between 1979 and 2005. For each cast the buoyancy frequency, $N$, was computed as described above. The maximum value of $N$ (corresponding to minimum buoyancy period) and the depth at which the maximum $N$ occurred were recorded for each cast. Casts were sorted by sampling month, and month-specific averages and standard deviations of $N$ and depth of maximum $N$ were calculated. The database for the chosen study area contained between one and twelve casts within each calendar month.

[16] The range of buoyancy frequency values was used to compare the internal wave characteristic angle, $s$, to the bottom slope, $a$, at Site A following Phillips [1977] and Davis et al. [2008]. We estimated $\alpha=\partial h / \partial x$, the change in bottom depth, $h$, over the horizontal distance, $x$, down the slope at two scales, first from the known locations along the transect of bottom-mounted instrument locations from 10 to $50 \mathrm{~m}$ and the north shore Site A slope, and second from the reef crest to $500 \mathrm{~m}$ depth from SIO/NOAA seafloor bathymetry data available in Google Earth (ver. 6.2.2.6613). The internal wave characteristic angle is calculated as

$$
\mathrm{s}=\left[\left(\omega^{2}-\mathrm{f}^{2}\right) /\left(\mathrm{N}^{2}-\omega^{2}\right)\right]^{0.5},
$$

where $\omega$ is the internal wave frequency ( 1.934 cycles per day for the semi-diurnal internal waves) $f$ is the local Coriolis frequency, and $N$ is the buoyancy frequency. When $\alpha / s \gg 1$ the reef slope is considered supercritical and a portion of incoming internal wave energy should be reflected offshore. When $\alpha / s \approx 1$ the reef slope is critical and incoming internal wave energy generates strong, near bottom velocity surges and traveling internal bores.

\section{Results}

[17] Variance ellipses representing the magnitude and orientation of water column integrated currents are shown in Figure 1. Water column currents varied strongly at tidal periodicities with peak velocities of 40 to $50 \mathrm{~cm} \mathrm{~s}^{-1}$ and root mean squared speeds on order of 8 to $10 \mathrm{~cm} \mathrm{~s}^{-1}$ oriented parallel to local isobaths on each of the three main shores of Moorea. Patterns of long-term water temperature variability at Moorea include seasonal fluctuations of approximately $3^{\circ}$ from $26^{\circ} \mathrm{C}$ to $29^{\circ} \mathrm{C}$ and complex patterns of higher frequency variation. From 2005 to 2010 the minimum daily average temperature typically occurred in Sep-Oct $\left(25.8^{\circ} \mathrm{C}\right.$ at $40 \mathrm{~m}$ depth to $25.9^{\circ} \mathrm{C}$ at $10 \mathrm{~m}$ depth); maximum daily average temperature occurred in Mar-Apr $\left(29.3^{\circ} \mathrm{C}\right.$ at $40 \mathrm{~m}$ depth to $29.7^{\circ} \mathrm{C}$ at $10 \mathrm{~m}$ depth). Figure 2 shows the temperature records from 10 to $50 \mathrm{~m}$ depths for Site A on the north shore from 2005 to 2010 . The 28 d running mean temperature exhibits annual periodicity with seasonal low temperatures typically occurring in Aug-Sep. The seasonal warming, especially in the surface waters, showed a general pattern of two annual periods of high temperature occurring in Jan-Feb and again in Mar-Apr. This can be seen clearly at 10 and $20 \mathrm{~m}$ depth in each of the study years and is also evident at 30 and $40 \mathrm{~m}$ in 2005 . The data also show evidence of interannual variation with cooler mean, maximum, and minimum temperatures in 2008 and warmer temperatures in 2006, 2007, and 2009.

[18] Superimposed on the seasonal temperature signal is a pattern of higher frequency variation that is strongly modulated across seasons and depths. When viewed on a time scale of hours to days it is clear that the thermal variation is produced by arrivals of cooler water, first at the deepest depths and then progressively up the reef slope. The onset of cooling events at the deep reef slope sampling stations ( 50 and $40 \mathrm{~m}$ depth) is typically characterized by a series of several discrete drops in temperature occurring as successive pulses separated by several minutes to tens of minutes. Typical duration of cooling events is one to several hours. The time series also show seasonal changes in the

Figure 2. Five-year time series of bottom temperature $\left({ }^{\circ} \mathrm{C}\right)$ sampled at 2 min interval at depths of (a and $\left.\mathrm{f}\right) 10$, (b and $\left.\mathrm{g}\right) 20$, (c and h) 30, (d and i) 40, and (e and j) $50 \mathrm{~m}$ on the reef slope at Site A, Jan 2005 to Mar 2010. Solid red lines show 28-d running mean temperature. $(\mathrm{k}-\mathrm{o})$ Expanded views of data subsets in Feb 2009 shown with corresponding to depths 10-50 m. Horizontal black bars on Figure $2 \mathrm{n}$ indicate periods for which current velocity data are shown in Figure 3. 


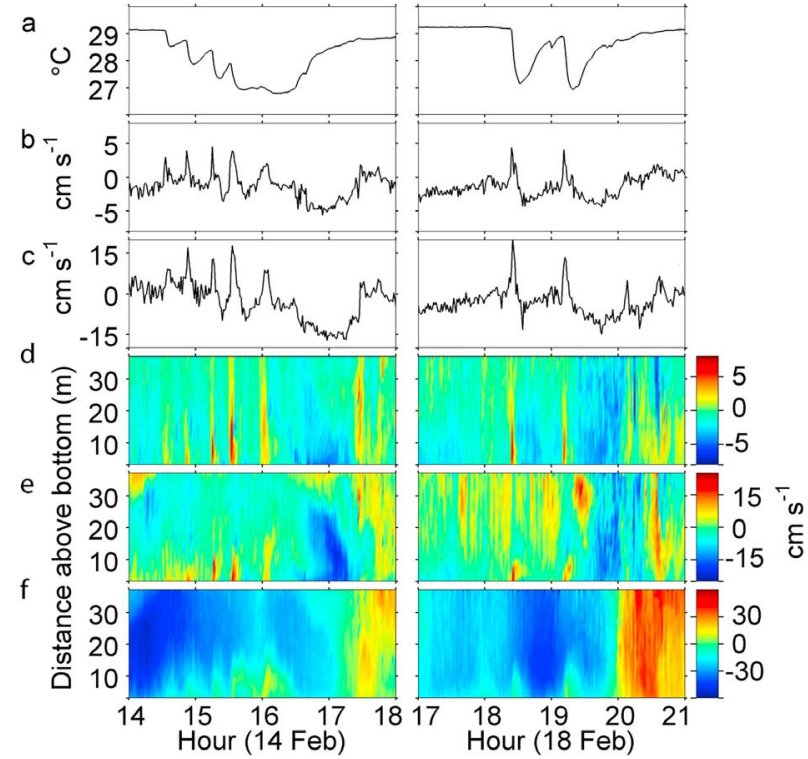

Figure 3. Examples of high frequency variation in bottom temperature and currents measured at north shore Site A during two 4-h time periods in Feb 2009: (left) $14 \mathrm{Feb}$ 2009 14:00-18:00 and (right) 18 Feb 2009 17:00-21:00 (Moorea local time). (a) Bottom temperature $\left({ }^{\circ} \mathrm{C}\right)$ at $40 \mathrm{~m}$ depth, (b) the vertical $\left(w, \mathrm{~cm} \mathrm{~s}^{-1}\right)$ component of velocity in the lowest $2-\mathrm{m}$ bin centered $3.5 \mathrm{~m}$ above the bottom, and (c) the cross-shore velocity component $\left(v, \mathrm{~cm} \mathrm{~s}^{-1}\right)$ in the same bin are shown. Full water column profiles in 2-m vertical bins of (d) vertical (w), (e) cross-shore (v), and (f) along-shore $(u)$ velocity components $\left(\mathrm{cm} \mathrm{s}^{-1}\right)$ are also shown. Velocity components plotted positive upward $(w)$, positive toward shore at $174^{\circ}(v)$, and positive toward west at $264^{\circ}(u)$.

high-frequency variation: fluctuations of $2^{\circ} \mathrm{C}$ to $4^{\circ} \mathrm{C}$ are common at the deeper depths from Dec-Apr in each year while conditions are far more constant and isothermal across the depths from Jun-Sep. The enlarged views of the temperature time series for Site A in Figure 2 show repeated, rapid cooling events at the 50 and $40 \mathrm{~m}$ depth isobaths that in some cases reach the 30 and $20 \mathrm{~m}$ isobaths. There is a clear pattern of individual cooling events - they are first observed at $50 \mathrm{~m}$ and then propagate up the reef slope to $40 \mathrm{~m}$, sometimes to $30 \mathrm{~m}$, and only occasionally to the 20 and the $10 \mathrm{~m}$ isobath. There is a clear decrease in the magnitude of the cooling events the cool water propagates up the reef slope.

[19] Examples of the bottom temperature and water column velocity data for two time periods in Feb 2009 on the north shore at Site A are shown in Figure 3. The sharp onset of cooling corresponds to repeated surges of positive (upward) near-bottom vertical velocity of approximately 2 to $9 \mathrm{~cm} \mathrm{~s}^{-1}$ and positive (shoreward) cross shore velocities of approximately 15 to $20 \mathrm{~cm} \mathrm{~s}^{-1}$. The subsequent warming corresponds to negative (downward) near-bottom vertical velocity up to $-5 \mathrm{~cm} \mathrm{~s}^{-1}$ and negative (offshore) cross-shore current velocities up to $-15 \mathrm{~cm} \mathrm{~s}^{-1}$. This indicates the movement of cool water masses vertically and horizontally onto and off of the reef with the changes in velocity concentrated in the bottom $8-10 \mathrm{~m}$ of the water column above the $40 \mathrm{~m}$ isobath. The pattern of temperature changes at the onset of many of the cooling events suggests packets of high frequency internal waves closely associated with the leading edge of the semidiurnal internal tide. These patterns of temperature changes including multiple pulses were common at all of the deep sampling sites around Moorea. Vertical excursions of isotherms above the $50 \mathrm{~m}$ isobath are illustrated for a 10-d segment of data in Jan 2010 in Figure 4. In these data the vertical position of the $28^{\circ} \mathrm{C}$ isotherm can be seen oscillating as much as 10 to $30 \mathrm{~m}$.

[20] A spectrogram for the 5-yr bottom temperature record from $40 \mathrm{~m}$ depth at Site A is shown in Figure 5. In each year there is a consistent pattern of increased spectral energy corresponding to the months of Oct-May with a prominent band evident at the $\mathrm{M}_{2}$ semi-diurnal frequency. In addition the increased variance in temperature from approximately Oct-May extends across a range of frequencies including energy that appears to extend both to a diurnal band and to high frequencies corresponding to periods on order of $10 \mathrm{~s}$ of min. Figure 6 shows power spectra for the data from 10 to $50 \mathrm{~m}$ depths at Site A separated into months Oct-May, and Jun-Sep. As in Figure 5 the variability in bottom temperatures is primarily concentrated at the semidiurnal frequency, $1.934 \mathrm{cpd}$, corresponding to a period of $12.4 \mathrm{~h}$. The

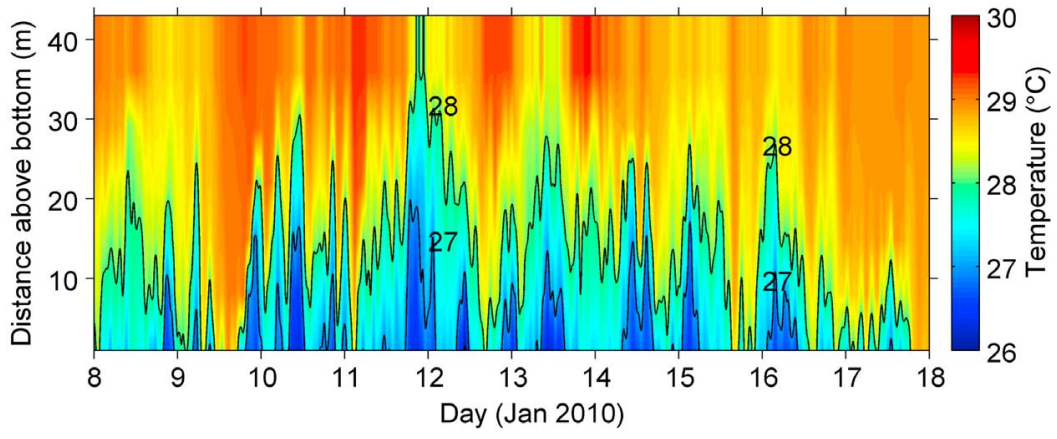

Figure 4. Vertical position of isotherms plotted as distance above bottom (m) during 8-18 Jan 2010. Data recorded by vertical string of temperature recorders at $7 \mathrm{~m}$ spacing deployed at $50 \mathrm{~m}$ depth on the reef slope at Site A. Solid lines superimposed on colored contours indicate the 28 and $27^{\circ} \mathrm{C}$ isotherms. 


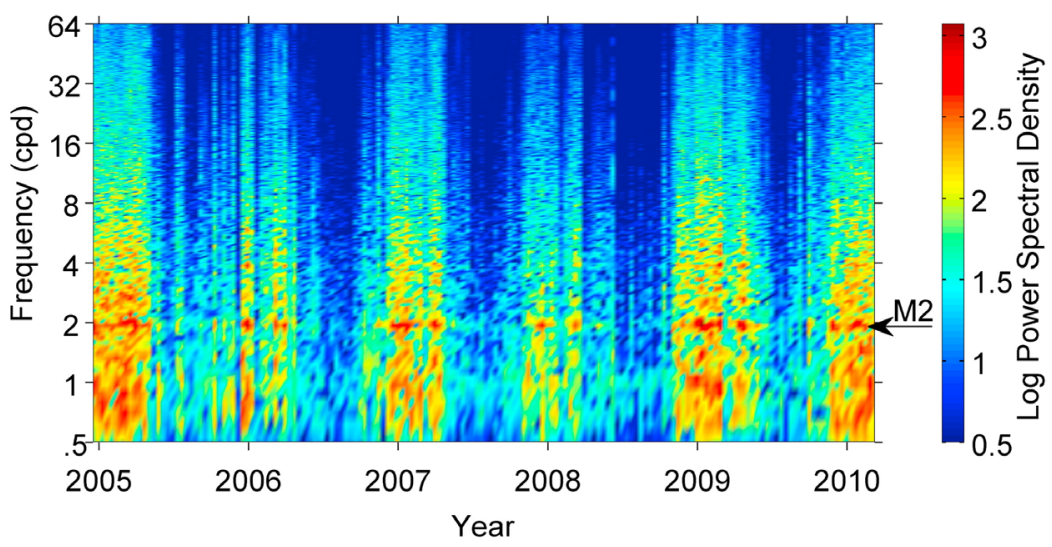

Figure 5. Spectrogram of temperature variation for north shore Site A at $40 \mathrm{~m}$ depth, Jan 2005-Mar 2010. Power spectral density normalized by frequency $\left({ }^{\circ} \mathrm{C}^{2}\right)$ shown on $\log$ scale as indicated by color bar, is plotted as a function of frequency (cycles per day) through time. M2 indicates the semi-diurnal frequency of $1.934 \mathrm{cpd}$.

amplitude of variation indicated by the height of the peak at the semidiurnal frequency increases markedly with increasing depth. Seasonal difference in variability is also evident as an approximately 2 orders of magnitude diminution of semi-diurnal variation in winter compared with summer at the 50,40 , and $30 \mathrm{~m}$ isobaths. At the $10 \mathrm{~m}$ isobath there is a dominant peak at the diurnal frequency $(1 \mathrm{cpd})$ and the height of this peak is equivalent between the seasons. The broadband increase in spectral levels during summer likely results from high frequency internal waves associated with the step-like temperature changes during upslope advection of cool water. Spectra calculated for the longer frequency components of the temperature signal (not shown) showed no distinct peaks at frequencies corresponding to periods of 2 to $96 \mathrm{~d}$. Patterns across depth of the daily temperature variance versus depth during summer and winter are shown in Figure 7. During summer there is a large increase in the mean daily temperature variance with increasing depth from 10 to $50 \mathrm{~m}$ depth. During winter the daily variance is greatly reduced and the differences among depths are minimal.

[21] The among-season variation at the semi-diurnal frequency evident in the temperature records is also evident in the current meter records. Figure 8a shows patterns across depth in the mean cross-shore shear for both the Oct-May and the Jun-Sep sampling periods across the 2005-2010 data set. In Oct-May there is a clear increase in mean shear toward the bottom of the water column above the $40 \mathrm{~m}$ sampling station. Figure $8 \mathrm{~b}$ shows power spectra for the mean cross-shore shear, with a prominent peak evident at the semi-diurnal frequency during Oct-May but absent in JunSep. The cross-spectrum between bottom temperature and cross-shore shear (not shown) also showed a distinct peak at the semi-diurnal frequency during Oct-May but not during Jun-Sep. We note that there are isolated instances during Jun-Sep when cross-shore and vertical currents do appear to transport water onto the reef with only small changes in temperature likely associated with the weak stratification in these periods. However, it is clear from the spectra that a consistent semi-diurnal peak in the current shear is not present during Jun-Sep.
[22] A 7-d segment of the velocity and temperature profiles from Site A with corresponding calculated gradient Richardson numbers are shown in Figure 9. Along-shore velocities were substantially greater than cross-shore velocities for most of the time period and normalized $R i$ was $>1$ in most time intervals indicating dominance by stability relative to shear. The record was punctuated by episodic incursions of comparatively cool near-bottom water, as well as periods where the entire water column was nearly isothermal. Short time periods when $R i<1$ occurred during strong alongshore flows, but not during the incursions of cool water which acted to increase vertical stratification. Mean profiles from Dec 2007 through Mar 2008 of the along-shore and cross-shore components of the squared velocity shear, as well as buoyancy calculated from the temperature stratification are shown in Figure 10. The along-shore current contributes substantially more to the total mean shear than the cross-shore velocities (Figure 10a). The greatest shear is near the bottom, likely due to interaction of the flow with the rough topography of the reef. Internal wave activity increased stratification in the lower water column, and the strongest density gradients were near the bottom as indicated by the profile of mean values (Figure $6 \mathrm{~b}$ ). We expect incursions of internal waves to the reef slope to enhance cross-shore vertical shear [Garrett and Munk, 1979]. While this is true in the instantaneous sense, in the case of Moorea's north shore it appears that in the average sense, the general mechanism is that the vertical and cross-shore excursions provide enhanced near bottom stratification, while the along-shore currents dominate the vertical shear and provide most of the energy for mixing.

[23] During the months of high internal wave activity observed at Site A very similar patterns are also evident at all of the other sites sampling sites around the island. Figure 11 shows thermal variation at $40 \mathrm{~m}$ depth at all 5 sampling sites around Moorea for the Sep 2009-Sep 2010. The patterns of variation are broadly similar at all sites, particularly the differences in variation among seasons and the decrease in variability beginning in Jun. There are also near-simultaneous cooling events at closely located sites. For example, at 


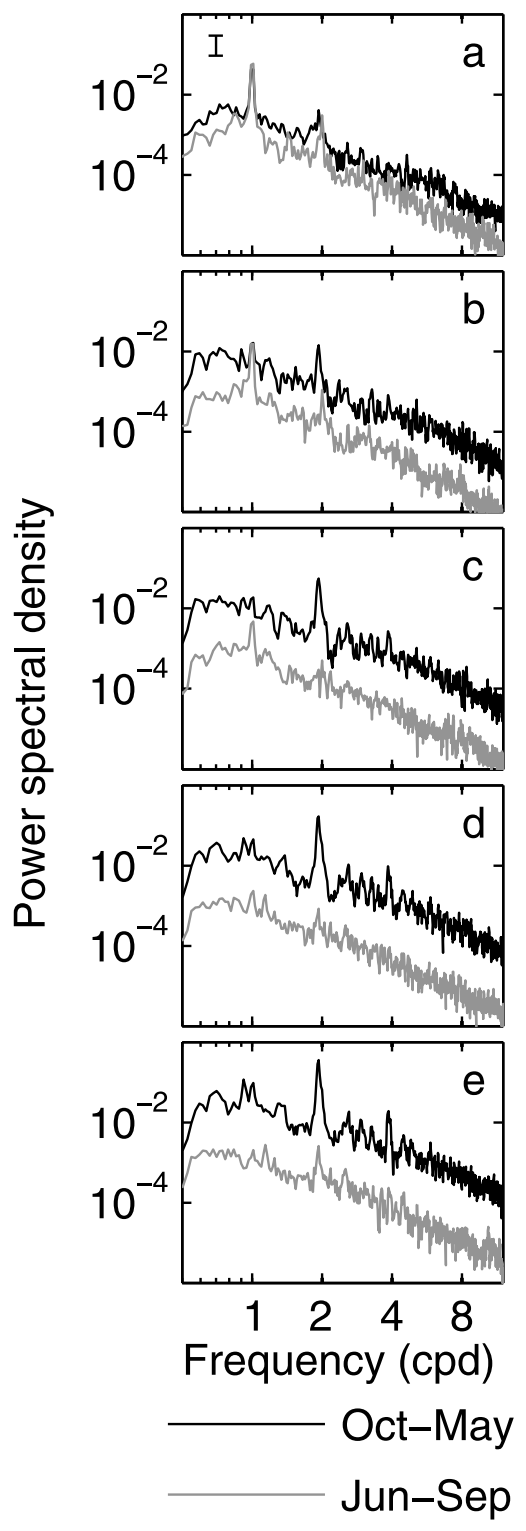

Figure 6. Power spectral density normalized by frequency is shown in units of ${ }^{\circ} \mathrm{C}^{2}$ for the temperature records from Jul 2007-Dec 2009 at north shore Site A. Spectra from (a) 10, (b) 20 , (c) 30, (d) 40, and (e) $50 \mathrm{~m}$ depth for data divided into two time periods, Oct-May (black line) and Jun-Sep (gray line) are shown. Frequency (horizontal axis) plotted in cycles per day. Vertical error bar in Figure 6a indicates $95 \%$ confidence interval on the log-y scale for all spectra. Prominent peak in Figures $6 \mathrm{~b}-6 \mathrm{e}$ is at frequency of $1.934 \mathrm{cpd}$, while peak in Figure 6a is at $1.0 \mathrm{cpd}$.

Sites B and C there are multiple cooling events with similar timing of onset and magnitude of cooling with approximately $1-2.5 \mathrm{~h}$ time shifts with the variation at Site $\mathrm{C}$ leading that at Site B (indicated with horizontal black bars in Figure 9). In contrast the variation at sites on opposite sides of the island is generally not as similar and the majority of the cooling events are not temporally coherent among sites.

[24] Figure 12 shows the semi-diurnal band-pass filtered temperature signals from the $40 \mathrm{~m}$ isobaths at Sites A-E are

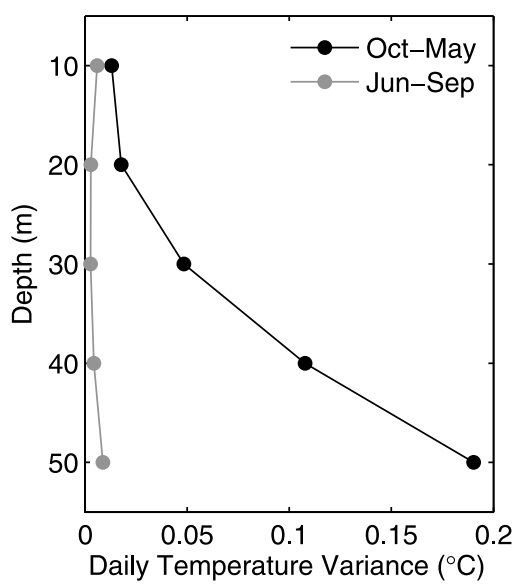

Figure 7. Mean daily variance in bottom temperature $\left({ }^{\circ} \mathrm{C}\right)$ across depth from 10 to $50 \mathrm{~m}$ at north shore Site A. Data are divided into two time periods, Oct-May (black line) and Jun-Sep (gray line) across the period Jul 2007-Dec 2009.

shown for a 5-week segment of Jan/Feb 2010. While there are time periods when the variation within the semi-diurnal band appears quite similar, especially among closely located Sites B and C, in general the amplitude and phase of the semi-diurnal variation are not tightly coherent among sites. Table 1 shows a matrix of the mean and maximum cross correlation coefficients for the Site A to E pairings across the 31-wk period from mid Dec 2009 to mid Jul 2010. Mean cross-correlation coefficients range from 0.36 to 0.52 and maximum correlation ranges from 0.68 to 0.87 for the $\mathrm{B}: \mathrm{C}$

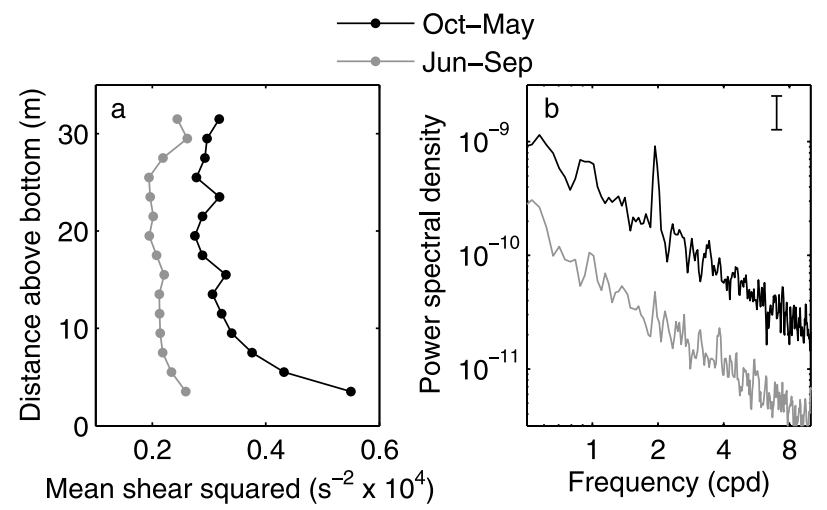

Figure 8. (a) Mean values of the cross-shore component of horizontal velocity shear $(\partial \mathrm{v} / \partial \mathrm{z})^{2}\left(\mathrm{~s}^{-2}\right)$ as function of distance above the bottom $(\mathrm{m})$ at north shore Site A. Data from current profilers deployed upward-looking at $40 \mathrm{~m}$ depth sampling the water column in $2 \mathrm{~m}$ vertical bins. Profiles of mean $(\partial \mathrm{v} / \partial \mathrm{z})^{2}$ are shown for time periods, Oct-May (black line) and JunSep (gray line) across the sampling period Jan 2005-Dec 2009. (b) Power spectral density of the $(\partial v / \partial z)^{2}$ time series from the bottom bin centered $3.5 \mathrm{~m}$ above the bottom for the Oct-May (black line) and Jun-Sep (gray line) time periods. Spectral density units normalized by frequency correspond to $\mathrm{s}^{-4}$. Prominent peak during Oct-May time period is centered at the semi-diurnal frequency of $1.934 \mathrm{cpd}$. 

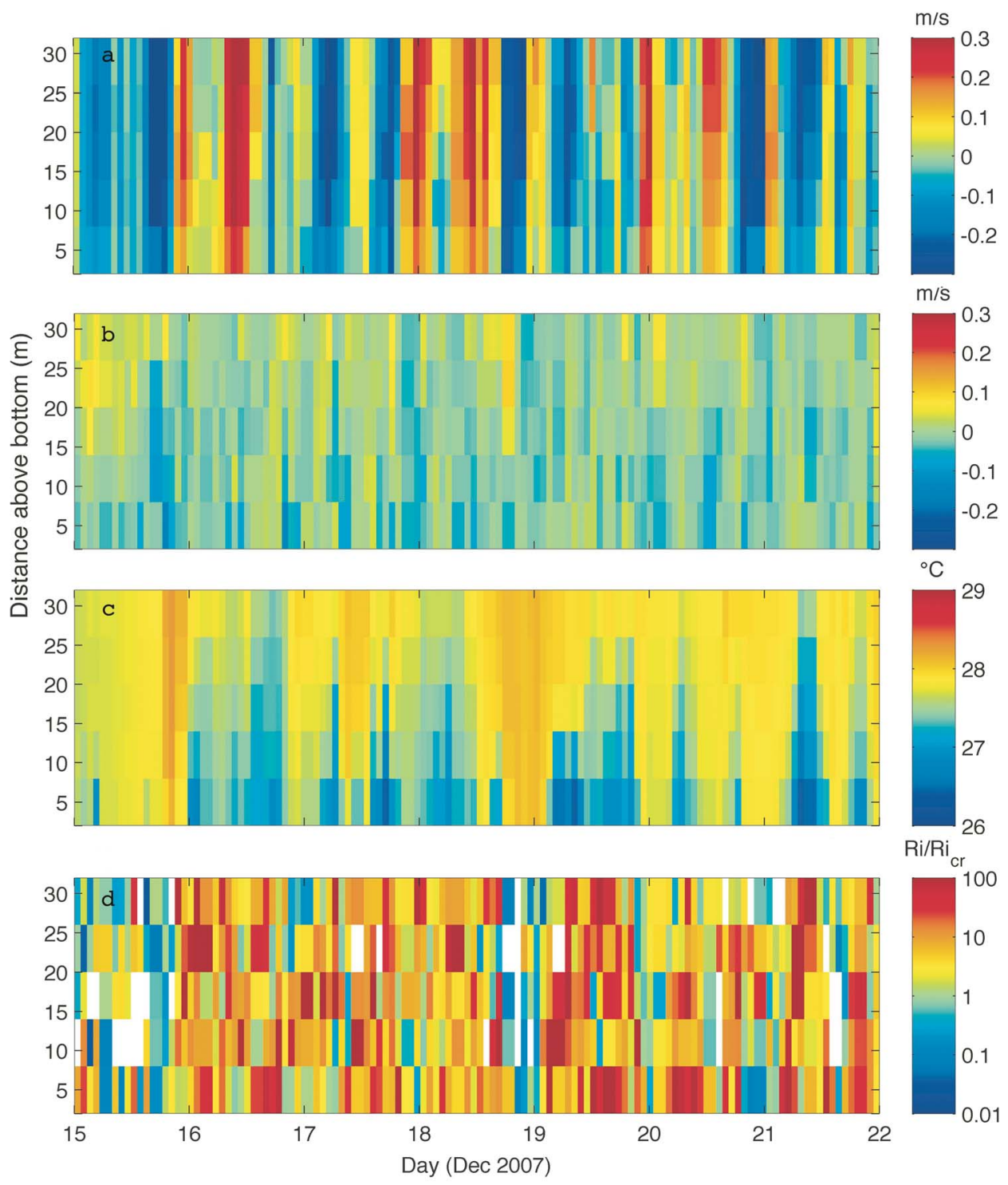

Figure 9. Vertical water column profiles of (a)along-shore velocity, (b) cross-shore velocity, (c) temperature, and (d) corresponding normalized Richardson number for the period 15-22 Dec 2007 at north shore Site A. Data from current profiler deployed upward-looking at $40 \mathrm{~m}$ depth sampling the water column in $2 \mathrm{~m}$ vertical bins. Normalized $R i>1$ indicates water column density stability dominating current shear, while $R i<1$ indicates potential for diapycnal mixing associated with horizontal shear.

and the D:E pairings. For the periods of highest crosscorrelation coefficient the corresponding lags ranged from 20 to $120 \mathrm{~min}$. However, across the 31-wk data period there were no consistent patterns in the lags. The cross-correlation coefficients for the band-pass filtered data agreed well with the mean squared coherence estimates at the semi-diurnal frequency, and the 7-d segments with high cross-correlation coefficients corresponded to times where the mean squared coherence at the semidiurnal frequency greatly exceeded the $95 \%$ confidence interval for a coherence of zero (implying a mean squared coherence that differs significantly from zero). Maximum mean squared coherence for the $\mathrm{B}: \mathrm{C}$ site pairing was 0.9. However, again there was no clear pattern in the phase relationships among sites and phase shift varied across a wide range of values corresponding to tens of minutes to several hours. While it appears in some time periods that similar cooling events impacted multiple sites (e.g., the events highlighted for Sites B and C in Figure 11 and also evident in the band-pass filtered data in Figure 12) in general the semi-diurnal temperature dynamics appear to be decoupled among sites. In contrast to this complex pattern of coherence in temperature variation, the coherence in the semi-diurnal surface water level was much simpler with a mean squared coherence value of 0.91 and phase shift of 39 min between Sites A and D, showing the surface tide at site A leading the tide at site D.

[25] The offshore water column stratification measured in Jan 2009 corresponded to a time of large semi-diurnal 

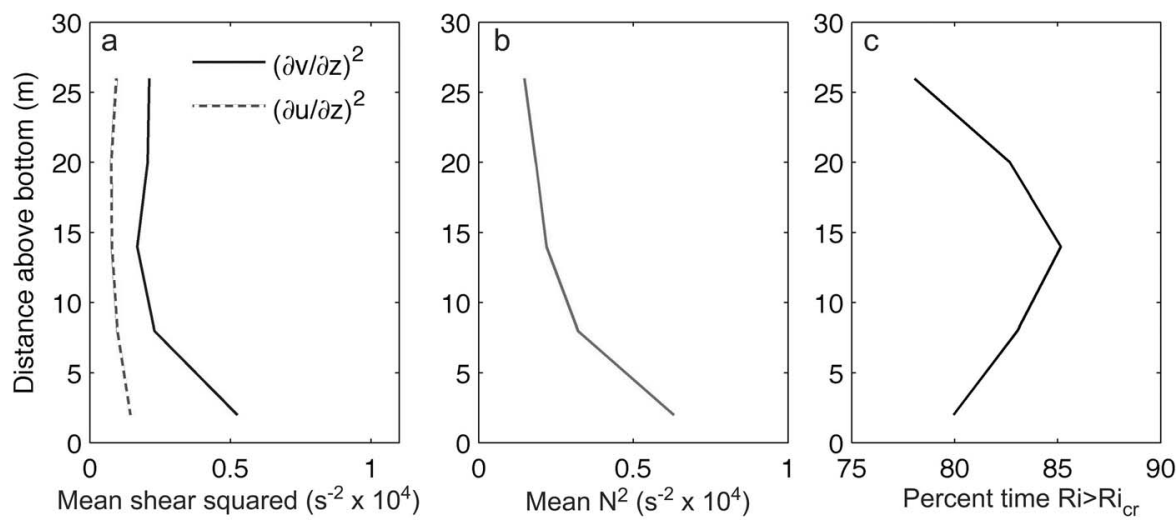

Figure 10. (a) Profiles of the along-shore $(\partial \mathrm{u} / \partial \mathrm{z})^{2}$ and cross-shore $(\partial \mathrm{v} / \partial \mathrm{z})^{2}$ components of mean squared current shear, (b) estimate vertical density stratification, and (c) percent time Richardson number was greater than $R i_{c r}$ indicating stability dominating shear. Data from upward-looking current profiler records and vertical temperature recorder string records at north shore Site A, $40 \mathrm{~m}$ bottom depth, for the time period Dec 2007 to Mar 2008.

thermal variation recorded on the reef slopes around the island. The average hydrographic profiles of temperature, salinity, density, chlorophyll $a$, and nitrate are shown in Figure 13. These show a broad thermocline extending to at least $500 \mathrm{~m}$. All of the measured hydrographic properties as well as chlorophyll $a$ and nitrate exhibited significant stratification from the surface to $500 \mathrm{~m}$ depth. Mean temperature varied from 29.1 at the surface, 27.4 at $50 \mathrm{~m}$ and declined monotonically to approximately $8.4^{\circ} \mathrm{C}$ at $500 \mathrm{~m}$. Salinity was 36.13 at the surface, increased to 36.42 at approximately $60 \mathrm{~m}$ and then decreased to 34.48 at $500 \mathrm{~m}$. Surface salinities higher than 36 are consistent with westward flow of the South Equatorial Current past Moorea. A broad pool of water with near-surface salinities exceeding 36.0 lies in the center of the subtropical gyre to east of the Society Islands (e.g., http://www-pord.ucsd.edu/whp atlas/pacific/maps/salnty/ pac10_salnty.jpg). Buoyancy frequency, $N$, was maximal at $42 \mathrm{~m}$ depth with a value of $9.9 \mathrm{cph}$. The averaged CTD profile also shows a clear subsurface fluorescence peak corresponding to $0.25 \mathrm{mg} \mathrm{L}^{-1}$ chlorophyll $a$ at $120 \mathrm{~m}$ and low values 0.09 at the surface and 0.08 at $270 \mathrm{~m}$. Nitrate concentration was essentially undetectable in surface waters, $1.59 \mathrm{umol} \mathrm{L}^{-1}$ at $200 \mathrm{~m}$ and increased to $20.76 \mathrm{umol} \mathrm{L}^{-1}$ at $500 \mathrm{~m}$. These CTD averages were sampled approximately every $2 \mathrm{~h}$ over $\sim 24 \mathrm{~h}$, so we assume it is likely that the sampling reflects the mean stratification and is not strongly aliased by vertical variations at semi-diurnal frequencies. The $27^{\circ} \mathrm{C}, 26^{\circ} \mathrm{C}$ and $25^{\circ} \mathrm{C}$ isotherms occurred at 56,76 and $108 \mathrm{~m}$ respectively. These temperatures span the cooler portion of the temperature range during internal wave cooling episodes at $40 \mathrm{~m}$ on the reef slope.

[26] Seasonal variation in water column stratification is shown in Figure 14. The maximum stratification occurred from Jan-Mar corresponding to $N$ of 9.5 to $12.5 \mathrm{cph}$ with minimum buoyancy periods of 4.8 to $6.3 \mathrm{~min}$. The average depth of maximum stratification was 50 to $60 \mathrm{~m}$ in the months Jan-May and then deepened to approximately $100 \mathrm{~m}$ in Jun-Jul and 150 to $200 \mathrm{~m}$ depth in Aug-Oct, and became shallower again in Nov-Dec. The variation in the maximum depth (shown as standard error bars in Figure 14) also varied among seasons with more closely constrained values in JanMay than in Jun-Oct.

[27] The slope angle $\alpha$ on the fore reef slopes of Moorea is quite steep, with values ranging from approximately 10 to $25 \%$ between the 10 and $40 \mathrm{~m}$ isobaths and increasing to approximately 33 to $55 \%$ between the reef crest and the $500 \mathrm{~m}$ isobaths. Estimated slope angle between the reef crest and $500 \mathrm{~m}$ for Sites A, B, C, D, and E were 35, 47, 55, 33, and $38 \%$ respectively. The ratio of $\alpha$ to internal wave characteristic angle $\mathrm{s}$ for semi-diurnal internal waves ranged from 9 to 45 for the range of measured buoyancy N. These values suggest the slope angle is supercritical relative to stratification all around Moorea and that a portion of the incident semi-diurnal internal wave energy will be reflected offshore.

\section{Discussion}

[28] The high frequency temperature and current observations analyzed here provide clear evidence of semi-diurnal and higher frequency internal waves impacting the deep portions of the fore reef slopes at all of the study sites around Moorea. The thermal variability is strongly modulated seasonally and during Oct-May is concentrated at the semidiurnal frequency and also extends to both lower and higher frequencies. The observed rapid cooling events correspond tightly to pulses of upward vertical velocities and onshore flow up the reef slopes with corresponding elevated crossshore current shear near the bottom of the water column. Subsequent warming events are tightly associated with downward vertical velocities and offshore flow down the reef slopes. The fluctuations in temperature of $1.5^{\circ} \mathrm{C}$ to $3^{\circ} \mathrm{C}$ on time scales of minutes to hours are of comparable magnitude to the fluctuations in daily average temperatures over entire years.

[29] Although our fixed sensor deployments were limited to maximum depths of $40 \mathrm{~m}$ at most sites and $50 \mathrm{~m}$ on the north shore the magnitude of thermal variation likely 

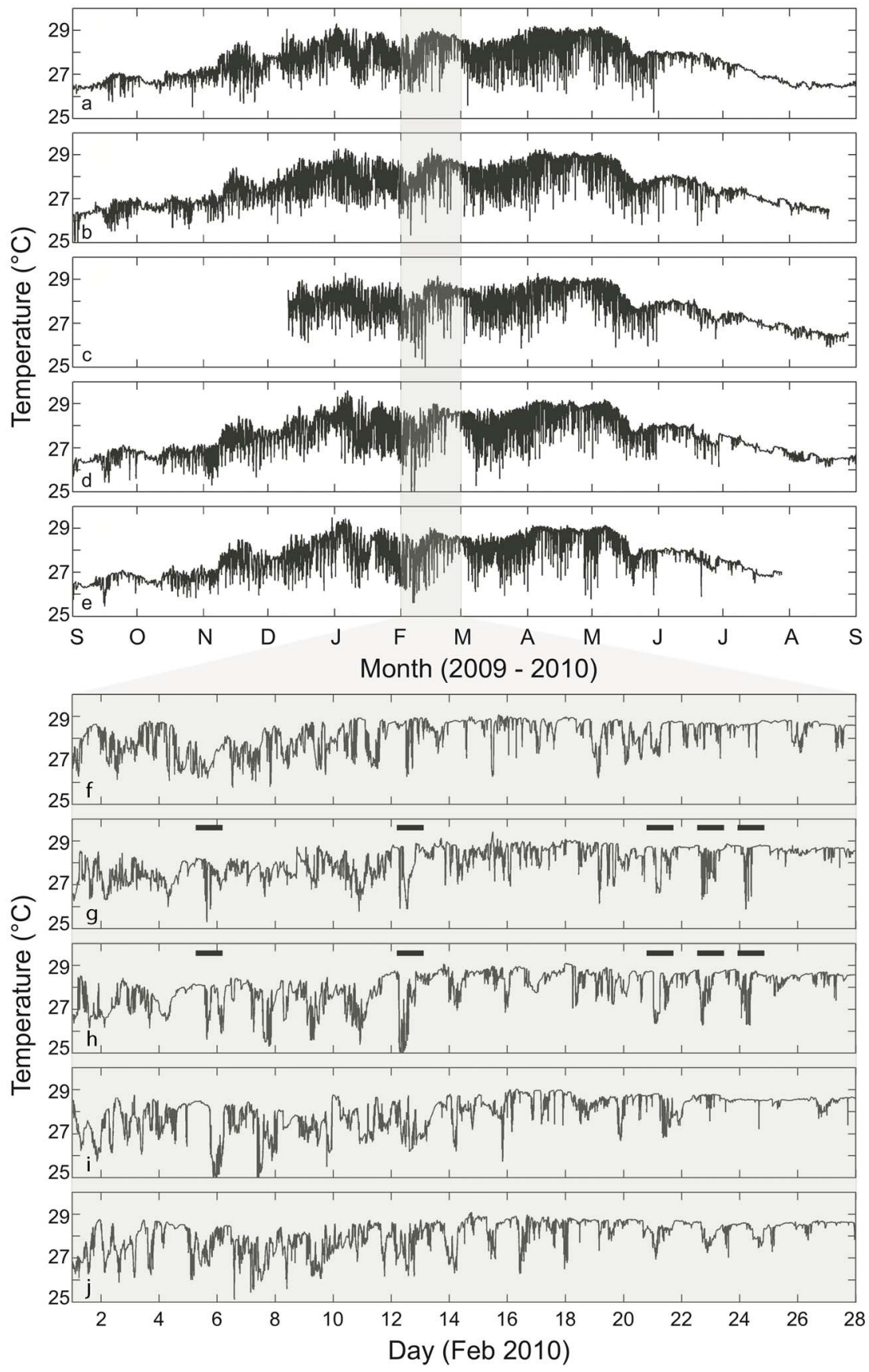

Figure 11. One-year record of bottom temperature $\left({ }^{\circ} \mathrm{C}\right)$ sampled at $2 \mathrm{~min}$ intervals at $40 \mathrm{~m}$ depth on each of five study sites around Moorea ((a-e) Sites A-E in Figure 1) from Sep 2009 to Sep 2010. (f-j) Expanded views of data from Feb 2010 are shown. Horizontal bars in Figures 11g and 11h highlight periods when the temperature variation was highly similar at closely spaced sites B and C.

increases at still greater depths. During austral summer (Dec-Apr) the maximum water column stratification occurs at 50 to $60 \mathrm{~m}$ depth, and continuous increases in density with increasing depth extend down at least as deep as $500 \mathrm{~m}$. We interpret the semi-diurnal fluctuations in temperature and near-bottom cross-shore shear on the reef slope as primarily low-mode internal waves that are likely traveling along the local maximum in density stratification. In addition, the occurrence of multiple higher frequency pulses often closely following the onset of cooling suggests packets of high frequency internal waves associated with the semi-diurnal variation. While we do not fully resolve the dynamics of these highest frequency events, the asymmetry between sharp cooling and more gradual warming within repeated pulses is suggestive of wave trains arriving with a bore-like or "solibore" structure [e.g., Hosegood and van Haren, 2004]. It is important also to note that the stratification in this system is characterized by a broad and continuous 


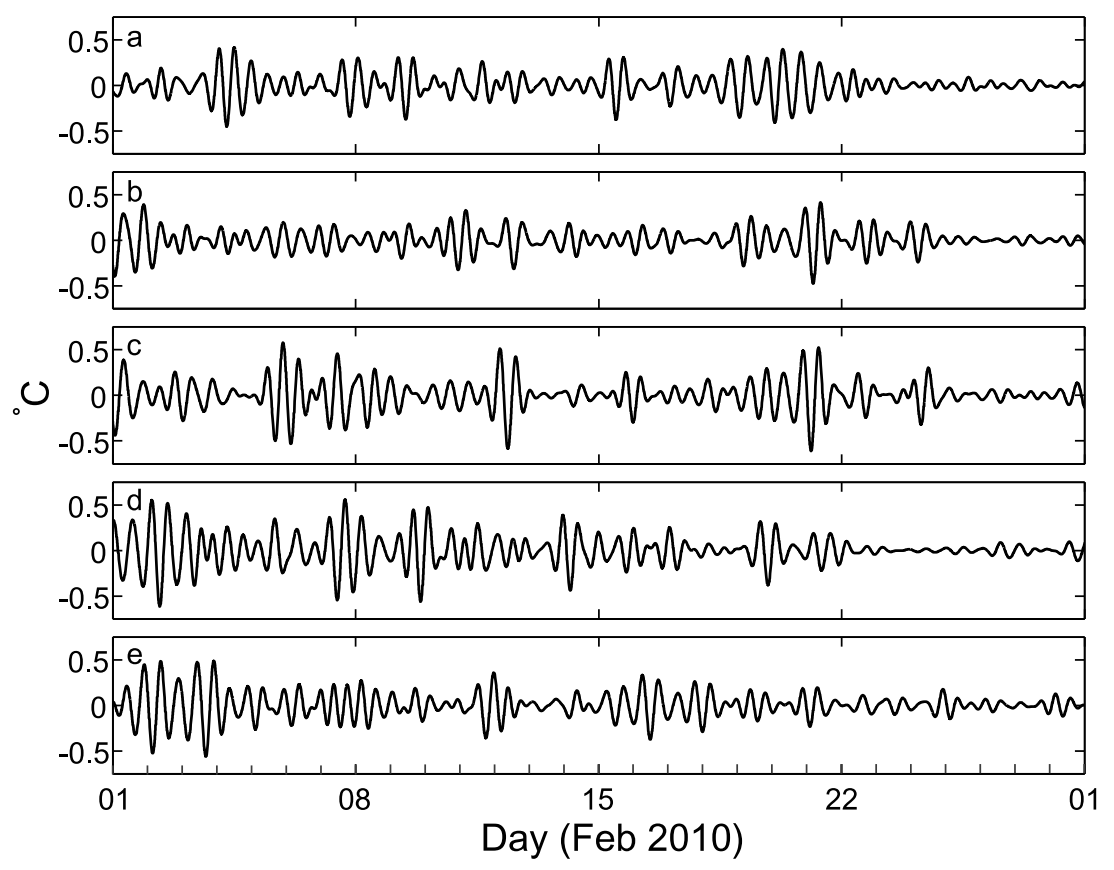

Figure 12. Semi-diurnal component of the bottom temperature records at $40 \mathrm{~m}$ depth for (a-e) Sites A-E during Feb 2010. Raw 2-min interval temperature data were band-pass filtered to remove variation outside of the semi-dirunal band defined as periods between 9 and $14 \mathrm{~h}$.

thermocline/pycnocline rather than the essentially twolayered stratification frequently observed in temperate and higher latitude locations. The local characteristics of vertical stratification will surely influence the structure of observed high frequency wave trains and presents an interesting opportunity for further study.

[30] The incidence of cooling events is clearly modulated at seasonal time scales in a manner that is consistent around the entire island. The period of strong internal wave activity in austral spring and summer (Oct-May), coincides with the period when vertical stratification is maximal and when the depth of maximum $N$ is shallowest (Figure 14). It appears likely that strengthening and shoaling of the pycnocline offshore of Moorea is a primary mechanism controlling the seasonal changes in internal wave activity observed around the island. However, with the present data we are unable to resolve whether significant internal wave activity does, in fact, occur at depths deeper than $50 \mathrm{~m}$ during austral winter (Jun-Sep). Future deployments of moorings in significantly deeper water (e.g., 100 to $200 \mathrm{~m}$ depth) maintained over at least an annual cycle could be a valuable next step in assessing this possibility. On shorter time scales, the variability in coherence among sites at semi-diurnal frequencies is complex, and at times shows evidence of cooling events that impact multiple sites with a consistent lag time in the arrival of cool water. However, the dominant pattern in most cases is a lack of coherence or consistent phase shifts among sites or across the sides of the island.

[31] These observations are new in several ways. The ability to resolve the seasonal internal wave climate at Moorea depends on continuous long-term observations, in this case a five-year time series of temperature and currents collected across a range of depths $(10$ to $50 \mathrm{~m})$ around the entire island. The interaction of barotropic currents with abrupt topography of the Society and Tuamotu Islands are expected to result in strong conversion of barotropic to baroclinic energy in the region [Ray and Mitchum, 1997; Egbert and Ray, 2001; Niwa and Hibiya, 2001], and prior sampling at Tahiti by Wolanski and Delesalle [1995a] showed internal wave impacts for deep portions of the reef slope. We can now see the context of those effects for Moorea at a seasonal scale. Results from two prior islandscale studies of internal waves are also relevant. Wolanski et al. [2004] described large amplitude (estimated at 50$100 \mathrm{~m}$ ) internal waves impacting two sites on opposite sides of Palau. They found no evidence for coherence of thermal variability among sites and suggested that the internal waves were not traveling around the island, but may have been locally generated on the island topography with energy radiating out to the open ocean. Roder et al. [2010, 2011] examined trophic consequences for corals of large differences in exposure to internal waves on the east and west

Table 1. Cross-Correlation Coefficients of Semi-diurnal Band Temperature Data From $40 \mathrm{~m}$ Depth for Paired Sites A-E

\begin{tabular}{lccccc}
\hline & $\mathrm{A}$ & $\mathrm{B}$ & $\mathrm{C}$ & $\mathrm{D}$ & $\mathrm{E}$ \\
\hline $\mathrm{A}$ & 1.0 & $0.37(0.70)$ & $0.36(0.68)$ & $0.37(0.71)$ & $0.40(0.84)$ \\
$\mathrm{B}$ & & 1.0 & $0.52(0.87)$ & $0.36(0.82)$ & $0.36(0.75)$ \\
$\mathrm{C}$ & & & 1.0 & $0.40(0.73)$ & $0.40(0.78)$ \\
$\mathrm{D}$ & & & & 1.0 & $0.38(0.87)$ \\
$\mathrm{E}$ & & & & & 1.0 \\
\hline
\end{tabular}

${ }^{\mathrm{a}}$ Mean cross-correlation values are shown with maxima in parentheses calculated over $n=31,7-\mathrm{d}$ data intervals between 15 Dec 2009 and 15 Jul 2010. 


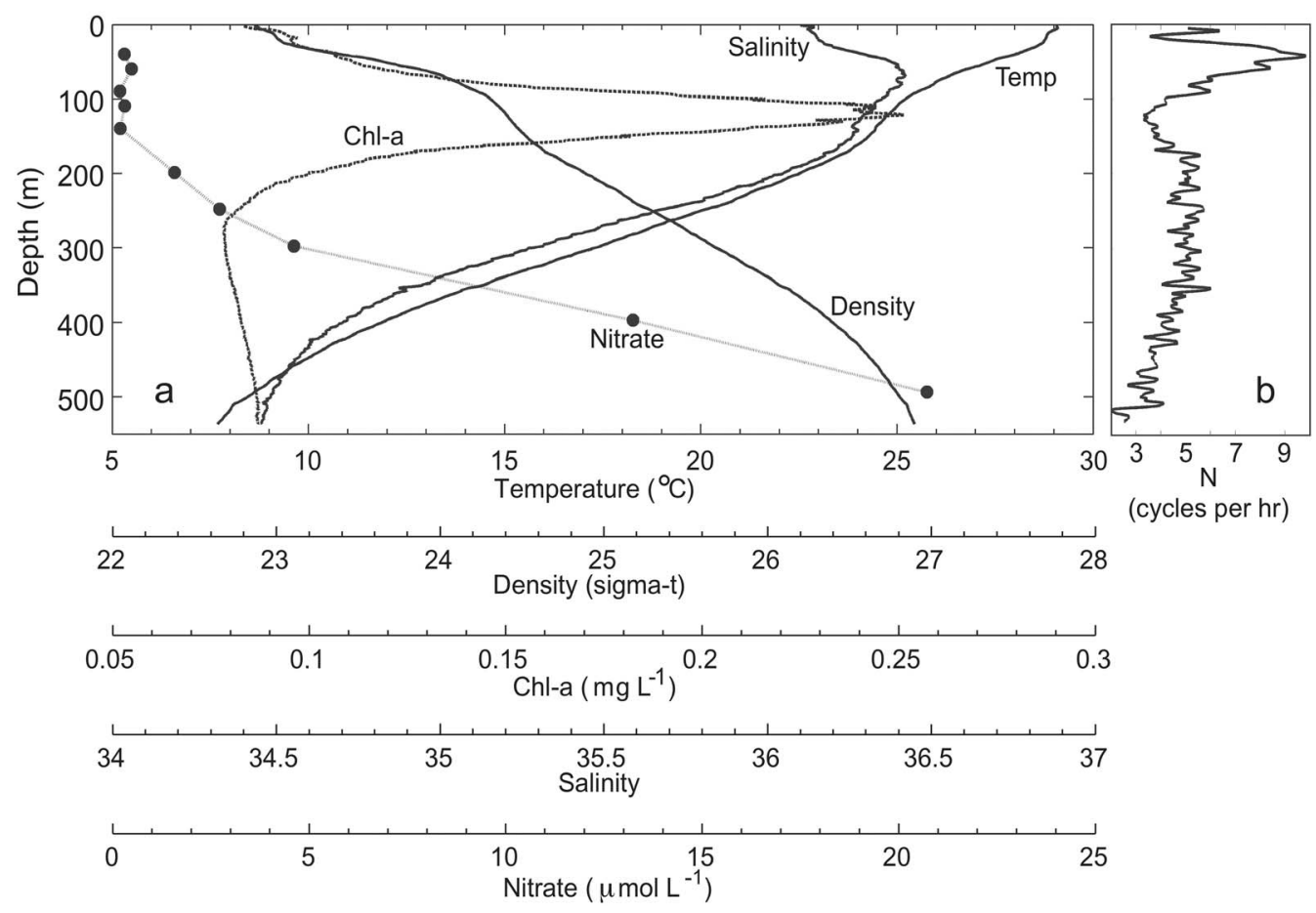

Figure 13. (a) Mean hydrographic profiles from $12 \mathrm{CTD}$ stations sampled to $550 \mathrm{~m}$ depth near Moorea on 25-26 Jan 2009. Labeled lines indicate temperature $\left({ }^{\circ} \mathrm{C}\right)$, density (sigma-t), salinity, and chlorophyll $a$ concentration $\left(\mathrm{mg} \mathrm{L}^{-1}\right)$. Solid circles indicate mean nitrate concentration $\left(\mu \mathrm{mol} \mathrm{L}^{-1}\right)$ measured from Niskin bottle samples collected at 50,100,150,200, 250,300, 400, and $500 \mathrm{~m}$ depth at 4 of the sampling stations. (b) Mean profile of buoyancy frequency, $N$, (cycles per hr) is indicated.

sides of multiple sites in the Similan Islands, Thailand, at the margin of the Andaman Sea. Unlike the relatively homogeneous distribution of internal wave impacts we observe at Moorea, in the Similan Islands east versus west facing sides of the islands correspond to large differences in internal wave exposure presumably associated with proximity to the energetic zones of internal wave generation in the Andaman Sea. Our data set also offers an indication of inter-annual variation. For example, as can be seen in Figure 2, there was variation among years in both the running mean temperatures and the extent of temperature variability all of which were lower in 2008 than in the other study years. While the mechanisms driving these inter-annual differences are presently unknown, collection of continuous, long-term time series is clearly essential for better determining the roles of long period and large scale processes on the local internal wave climate. Long-term observations can also provide a context for considering how changes in stratification associated with large-scale periodic fluctuations at ocean basin scales and with climate change may impact dynamics at local scales.

[32] Although the present observations do not resolve the mechanisms of internal wave generation impacting Moorea, the observations indicate clear seasonal consistency in the magnitude and general timing of internal wave activity around the island. A clear asymmetry suggesting a prevailing direction or a strong, nearby source of internal wave energy is not observed. Nor are there obvious differences among sides of the island that might suggest, for example,

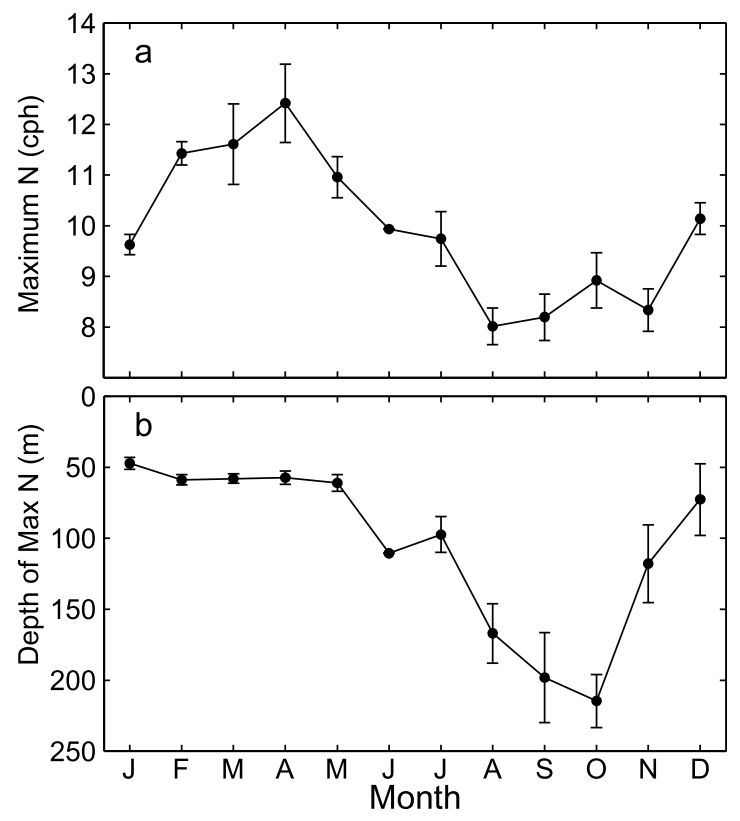

Figure 14. (a) Monthly mean ( \pm std. error) of the water column maximum buoyancy frequency, $N$, (cycles per hr) and (b) monthly mean $( \pm$ std. error) of the depth $(\mathrm{m})$ of the maximum $N$. Values calculated from total of 64 CTD cast stations located within $2^{\circ}$ of Moorea (as shown in Figure 1) included in the World Ocean Data Base for the period 1979 to 2005. 
sheltering of Moorea by the larger island of Tahiti. Instead, the consistency of events around the island suggests sources of internal waves spread over a broad range of directions and distances. This appears consistent with modeling results for this region [Niwa and Hibiya, 2001]. Similarly, the lack of any clear low frequency spectral peaks indicating modulation of the internal wave signal at long tidal frequencies such as the fortnightly spring-neap cycle suggest a broad range of sources including distant sites rather than a limited number of local sources. Extensive research on the somewhat analogous Hawaiian Islands chain provides insight into processes that may be driving variation observed at Moorea. On the south coast of Oahu a highly energetic internal wavefield produces strong vertical displacements and enhanced near-bottom currents at semi-diurnal frequencies [Eich and Merrifield, 2004]. A series of empirical studies and numerical simulations have resolved the highly energetic internal wavefield generated at multiple locations along the Hawaiian Islands chain [e.g., Chiswell, 1994; Holloway and Merrifield, 1999; Merrifield et al., 2001; Eich and Merrifield, 2004]. Large internal waves appear to be generated at multiple points along the Hawaiian Ridge where strong tidal flows within the densitystratified water column intercept abrupt topographic features [Merrifield et al., 2001]. The hydrographic structure and continuous density stratification at these locations are conducive to the generation of energetic upslope jets of cool water.

[33] The variability we observe at Moorea may result from driving physics similar to that described for the Hawaiian Islands and it seems likely that the internal waves observed around the island originate from multiple zones of generation local to the bathymetry of Moorea and Tahiti. However, unlike observations at Oahu which show strong spatial variation and hot spots of internal wave generation, the internal wavefield around Moorea appears to be relatively homogeneous at least among shores at the relatively shallow depths resolved in the present study. Occasional packets of internal waves with alongshore coherence in temperature variability were observed at some site pairs. For example Figures 11 and 12 show events with apparent coherence between Sites $\mathrm{B}$ and $\mathrm{C}$ on the east side of Moorea. This coherence was most frequently observed for this site pair, and may suggest a source of internal wave generation offshore, perhaps on Tahiti which lies $16 \mathrm{~km}$ away from this side of the Moorea.

[34] The broad-scale changes in stratification likely result from seasonal variation in surface heating and may also be enhanced by passage of mesoscale eddies and variation in evaporation and rainfall associated with the Intertropical Convergence Zone. Rainfall is strongly seasonal in this region, and is particularly strong from Dec-Mar in most years. The mean hydrographic profile shown in Figure 13 shows low surface salinity relative to the salinity maximum at approximately 50 to $60 \mathrm{~m}$ depth. Reduced salinity near the surface contributes to density stratification within the top $50 \mathrm{~m}$ of the water column. How stratification may change at inter-annual and longer time scales is not clear, but if enhanced warming leads to stronger surface stratification we may expect an increase in internal wave activity in the region. Conversely, in anomalously cool years such as 2008 or under a scenario of long-term climate cooling, for example during global ice ages, we can speculate there might be a decrease in stratification and decreased internal wave activity. Similarly, inter-annual changes in precipitation that contribute to the changes in density stratification of the water column may have effects for internal wave activity on the reef slopes.

[35] The present study also provides a context of temporal and spatial variation in forcing for considering the potential biological and ecological impacts of internal waves on Moorea's coral reefs. While our study is limited to a single island, the patterns of temperature and current variation we observe at Moorea may be general to neighboring sites such as Tetiaroa Atoll to the north, Maiao Iti to the west, and the large number of islands and atolls in this region of the central South Pacific. Geologists and biologists have long considered fundamental questions regarding the formation and maintenance of coral reefs in oligotrophic waters on oceanic islands such as Moorea. In fact, the view of Moorea and its surrounding reefs seen from Tahiti was central to Darwin's early insight, developed during the Beagle voyage, into reef formation in relation to island subsidence [Stoddart, 1962; Egerton, 2010]. More recently, it has been recognized since the early 1980s that internal waves may have significant impacts in coral reef ecosystems [e.g., Wolanski and Pickard, 1983]. Because corals typically inhabit warm, shallow, nutrient-poor waters, the potential to move cooler, nutrient-rich water onto reefs may impact overall productivity and the community balance between for example corals and macroalgae. In Moorea it appears unlikely that the arrival of $25^{\circ}$ to $27^{\circ}$ isotherms, uplifted on order 35 to perhaps $70 \mathrm{~m}$, is sufficient to represent a large direct input of dissolved nutrients because the top of the nutricline appears to be significantly deeper at a depth of approximately $200 \mathrm{~m}$. However, the fluorescence data do suggest biomass within the subsurface chlorophyll maximum layer may be transiently advected onto the reef slope. While the subsurface chlorophyll maximum layer is not necessarily a water column particle or biomass maximum, biological production there is likely supported by a balance between available light in the deep portion of the euphotic zone and nutrient availability associated with the top of the nutricline. If organic particles associated with the subsurface chlorophyll maximum are advected onto the deep reef slopes and captured by benthic suspension feeders a pathway of allocthonous production reaching the reef community may be established. The repeated arrival of semi-diurnal internal waves on the deep portions of the reefs may constitute an indirect connection between the reef biota and the deep, offshore pool of oceanic inorganic nutrients. Thus, the observations described here can set a context for future studies of direct and indirect connections between island coral reefs and the oceanic organic and inorganic nutrient pools.

[36] Acknowledgments. This research was supported through NSF funding to the Moorea Coral Reef Long-term Ecological Research Project and minigrant awards from that project to JJL, as well as NSF award OCE-0927448 to JJL. Hydrographic sampling was supported through the Three Seas Program of Northeastern University and the Sea Education Association. We gratefully acknowledge logistic and field assistance from, M. Murray, S. Genovese, L. Kintzing, K. Hanson, A. Wyatt, K. Seydel, and A. Brooks. The manuscript was improved by helpful comments of two anonymous reviewers, comments by A. Wyatt, and through discussion with J. MacKinnon.

\section{References}

Adam, T. C., R. J. Schmitt, S. J. Holbrook, A. J. Brooks, P. J. Edmunds, R. C. Carpenter, and G. Bernardi (2011), Herbivory, connectivity, and ecosystem resilience: Response of a coral reef to a large-scale perturbation, PLoS ONE, 6(8), E23717, doi:10.1371/journal.pone.0023717. 
Apel, J. R. (1988), Principles of Ocean Physics, Int. Geophys. Ser., vol. 38, Academic Press, London.

Apel, J. R., and D. M. Farmer (2002), Nonlinear solitary internal waves, Global Ocean Associates Rep. 2000-2, Global Ocean Assoc., Silver Spring, Md

Bak, R. P. M., G. Nieuwland, and E. H. Meesters (2005), Coral reef crisis in deep and shallow reefs: 30 years of constancy and change in reefs of Curacao and Bonaire, Coral Reefs, 24, 475-479, doi:10.1007/s00338005-0009-1.

Cacchione, D. A., L. F. Pratson, and A. S. Ogston (2002), The shaping of continental slopes by internal tides, Science, 296, 724-727, doi:10.1126/ science. 1069803.

Chiswell, S. M. (1994), Vertical structure of the baroclinic tides in the central North Pacific subtropical gyre, J. Phys. Oceanogr., 24, 2032-2039, doi:10.1175/1520-0485(1994)24[2032:VSOTBT]2.0.CO;2.

Davis, K. A., J. J. Leichter, J. L. Hench, and S. G. Monismith (2008), Effects of western boundary current dynamics on the internal wave field of the southeast Florida shelf, J. Geophys. Res., 113, C09010, doi:10.1029/ 2007JC004699.

Dymond, J. (1975), K-Ar ages of Tahiti and Moorea, Society Islands, and implications for the hot-spot model, Geology, 3, 236-240, doi:10.1130/ 0091-7613(1975)3<236:KAOTAM $>2.0$. CO 2 .

Egbert, G. D., and R. D. Ray (2001), Estimates of M2 tidal dissipation from TOPEX/Poseidon altimeter data, J. Geophys. Res., 106, 22,475-22,502, doi:10.1029/2000JC000699

Egerton, F. N. (2010), History of ecological sciences, part 37: Charles Darwin's Voyage on the Beagle, Bull. Ecol. Soc. Am., 91, 398-431, doi:10.1890/0012-9623-91.4.398.

Eich, M. L., and M. A. Merrifield (2004), Structure and variability of semidiurnal internal tides in Mamala Bay, Hawaii, J. Geophys. Res., 109, C05010, doi:10.1029/2003JC002049.

Emery, W. J., and R. E. Thomson (1997), Data Analysis Methods in Physical Oceanography, Pergamon, Kidlington, U. K.

Farmer, D. M., and L. Armi (1999), The generation and trapping of solitary waves over topography, Science, 283, 188-190, doi:10.1126/science.283. 5399.188 .

Garrett, C., and E. Kunze (2007), Internal tide generation in the deep ocean, Annu. Rev. Fluid Mech., 39, 57-87, doi:10.1146/annurev.fluid.39.050905. 110227

Garrett, C., and W. Munk (1979), Internal waves in the ocean, Annu. Rev. Fluid Mech., 11, 339-369, doi:10.1146/annurev.fl.11.010179.002011.

Helfrich, K. R., and W. K. Melville (2006), Long nonlinear internal waves, Аnпu. Rev. Fluid Mech., 38, 395-425, doi:10.1146/annurev.fluid.38 050304.092129.

Hench, J. L., J. J. Leichter, and S. G. Monismith (2008), Episodic circulation and exchange in a wave-driven coral reef and lagoon system, Limnol. Oceanogr., 53, 2681-2694.

Holloway, P. E., and M. A. Merrifield (1999), Internal tide generation by seamounts, ridges, and islands, J. Geophys. Res., 104(C11), 25,937-25,951, doi:10.1029/1999JC900207.

Hosegood, P., and H. van Haren (2004), Near-bed solibores over the continental slope in the Faeroe-Shetland Channel, Deep Sea Res., Part II, 51, 2943-2971, doi:10.1016/j.dsr2.2004.09.016.

Leichter, J. J., G. Shellenbarger, S. J. Genovese, and S. R. Wing (1998), Breaking internal waves on a Florida (USA) coral reef: A plankton pump at work?, Mar. Ecol. Prog. Ser., 166, 83-97, doi:10.3354/meps166083.

Leichter, J. J., H. L. Stewart, and S. L. Miller (2003), Episodic nutrient transport to Florida coral reefs, Limnol. Oceanogr., 48, 1394-1407, doi:10.4319/10.2003.48.4.1394.

Leichter, J. J., B. Helmuth, and A. M. Fischer (2006), Variation beneath the surface: Quantifying complex thermal environments on coral reefs in the Caribbean, Bahamas and Florida, J. Mar. Res., 64, 563-588, doi:10.1357/ 002224006778715711 .
Lucas, A. J., P. J. S. Franks, and C. L. Dupont (2011), Horizontal internaltide fluxes support elevated phytoplankton productivity over the inner continental shelf, Limnol. Oceanogr. Fluids Environ., 1, 56-74, doi:10.1215/21573698-1258185.

Merrifield, M. A., P. E. Holloway, and T. M. S. Johnston (2001), The generation of internal tides at the Hawaiian Ridge, Geophys. Res. Lett., 28 , 559-562, doi:10.1029/2000GL011749.

Niwa, Y., and T. Hibiya (2001), Numerical study of the spatial distribution of the M2 internal tide in the Pacific Ocean, J. Geophys. Res., 106(C10), 22,441-22,449, doi:10.1029/2000JC000770.

Phillips, O. M. (1977), The Dynamics of the Upper Ocean, Cambridge Univ Press, Cambridge, U. K.

Pineda, J. (1991), Predictable upwelling and the shoreward transport of planktonic larvae by internal tidal bores, Science, 253, 548-551, doi:10.1126/science.253.5019.548

Pineda, J. (1994), Internal tidal bores in the nearshore: Warm-water fronts, seaward gravity currents and the onshore transport of neustonic larvae, J. Mar. Res., 52, 427-458, doi:10.1357/0022240943077046.

Ray, R. D., and G. T. Mitchum (1997), Surface manifestation of internal tides in the deep ocean: Observations from altimetry and island gauges, Prog. Oceanogr., 40, 135-162, doi:10.1016/S0079-6611(97)00025-6.

Roder, C., L. Fillinger, C. Jantzen, G. M. Schmidt, S. Khokiattiwong, and C. Richter (2010), Trophic response of corals to large amplitude internal waves, Mar. Ecol. Prog. Ser., 412, 113-128, doi:10.3354/meps08707.

Roder, C., C. Jantzen, G. M. Schmidt, G. Kattner, N. Phongsuwan, and E. Richter (2011), Metabolic plasticity of the corals Porites lutea and Diploastrea heliopora exposed to large amplitude internal waves, Coral Reefs, 30, 57-69, doi:10.1007/s00338-011-0722-x.

Rougerie, F., and J. Rancher (1994), The Polynesian South Ocean: Features and circulation, Mar. Pollut. Bull., 29, 14-25, doi:10.1016/0025-326X (94)90421-9.

Sandstrom, H., and J. A. Elliott (1984), Internal tide and solitons on the Scotian shelf: A nutrient pump at work, J. Geophys. Res., 89, 6415-6426, doi:10.1029/JC089iC04p06415.

Shanks, A. L., J. Largier, L. Brink, J. Brubaker, and R. Hooff (2000), Demonstration of the onshore transport of larval invertebrates by the shoreward movement of an upwelling front, Limnol. Oceanogr., 45 , 230-236, doi:10.4319/lo.2000.45.1.0230.

St. Laurent, L., and C. Garrett (2002), The role of internal tides in mixing the deep ocean, J. Phys. Oceanogr., 32, 2882-2899, doi:10.1175/15200485(2002)032<2882:TROITI $>2.0$.CO 2 .

St. Laurent, L., and J. Nash (2004), An examination of the radiative and dissipative properties of the internal tides, Deep Sea Res., Part II, 51, 3029-3042, doi:10.1016/j.dsr2.2004.09.008.

Stoddart, D. R. (1962), Coral islands, by Charles Darwin: With introduction, map and remarks, Atoll Res. Bull., 88, 1-20.

Trauth, M. H. (2010), MATLAB ${ }^{\circledR}$ Recipes for Earth Science, 3rd ed., Springer, Potsdam, Germany, doi:10.1007/978-3-642-12762-5.

Wolanski, E., and B. Delesalle (1995a), Upwelling by internal waves, Tahiti, French Polynesia, Cont. Shelf Res., 15, 357-368, doi:10.1016/ 0278-4343(93)E0004-R.

Wolanski, E., and B. Delesalle (1995b), Wind-driven upwelling in Opunohu Bay, Moorea, French Polynesia, Estuarine Coastal Shelf Sci., 40, 57-66, doi:10.1016/0272-7714(95)90013-6.

Wolanski, E., and G. L. Pickard (1983), Upwelling by internal tides and Kelvin waves at the continental shelf break on the Great Barrier Reef, Aust. J. Mar. Freshwater Res., 34, 65-80, doi:10.1071/MF9830065.

Wolanski, E., P. Colin, J. Naithani, E. Deleersnijder, and Y. Golbuu (2004), Large amplitude, leaky, island-generated, internal waves around Palau, Micronesia, Estuarine Coastal Shelf Sci., 60, 705-716, doi:10.1016/j. ecss.2004.03.009. 